University of Wollongong

Research Online

Faculty of Engineering - Papers (Archive)

Faculty of Engineering and Information

Sciences

$1-1-2010$

\title{
Enhancement of Co substitution induced by Eu codoping in ZnO-based diluted magnetic semiconducting thin films
}

P Photongkam

University of NSW

Y B Zhang

The University of New South Wales

M.H.N Assadi

The University of New South Wales

S Li

The University of New South Wales

D Yu

Australian Nuclear Science Technology Sydney

See next page for additional authors

Follow this and additional works at: https://ro.uow.edu.au/engpapers

Part of the Engineering Commons

https://ro.uow.edu.au/engpapers/2799

\section{Recommended Citation}

Photongkam, P; Zhang, Y B; Assadi, M.H.N; Li, S; Yu, D; lonescu, Mihail; and Pan, Alexey V.: Enhancement of Co substitution induced by Eu codoping in ZnO-based diluted magnetic semiconducting thin films 2010, 033909-1-033909-4.

https://ro.uow.edu.au/engpapers/2799

Research Online is the open access institutional repository for the University of Wollongong. For further information contact the UOW Library: research-pubs@uow.edu.au 
Authors

P Photongkam, Y B Zhang, M.H.N Assadi, S Li, D Yu, Mihail Ionescu, and Alexey V. Pan 


\section{AIP $\mid$ Appilied Physics}

\section{Enhancement of Co substitution induced by Eu codoping in ZnO-based}

diluted magnetic semiconducting thin films

P. Photongkam, Y. B. Zhang, M. H. N. Assadi, S. Li, D. Yu et al.

Citation: J. Appl. Phys. 107, 033909 (2010); doi: 10.1063/1.3298507

View online: http://dx.doi.org/10.1063/1.3298507

View Table of Contents: http://jap.aip.org/resource/1/JAPIAU/v107/i3

Published by the American Institute of Physics.

Additional information on J. Appl. Phys.

Journal Homepage: http://jap.aip.org/

Journal Information: http://jap.aip.org/about/about_the_journal

Top downloads: http://jap.aip.org/features/most_downloaded

Information for Authors: http://jap.aip.org/authors

\section{ADVERTISEMENT}
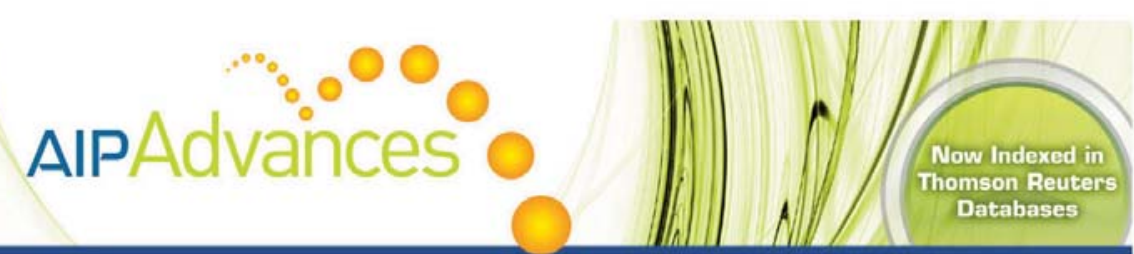

\section{Explore AIP's open access journal: •Rapid publication \\ - Article-level metrics \\ Post-publication rating and commenting}




\title{
Enhancement of Co substitution induced by Eu codoping in ZnO-based diluted magnetic semiconducting thin films
}

\author{
P. Photongkam, ${ }^{1}$ Y. B. Zhang, ${ }^{1}$ M. H. N. Assadi, ${ }^{1}$ S. Li, ${ }^{1, a)}$ D. Yu, ${ }^{2}$ M. Ionescu, ${ }^{2}$ and \\ A. V. $\operatorname{Pan}^{3}$ \\ ${ }^{1}$ School of Materials Science and Engineering, The University of New South Wales, Sydney, \\ New South Wales 2052, Australia \\ ${ }^{2}$ Australian Nuclear Science and Technology Organization, Sydney, New South Wales 2234, Australia \\ ${ }^{3}$ Institute for Superconducting and Electronic Materials, University of Wollongong, Wollongong, \\ New South Wales 2522, Australia
}

(Received 28 October 2009; accepted 29 December 2009; published online 8 February 2010)

\begin{abstract}
To avoid the occurrence of doped magnetic ion clustering is a challenge in fabrication of diluted magnetic semiconductors (DMSs). In this work, we report the intrinsic ferromagnetic behavior in Co-doped $\mathrm{ZnO}$ DMSs induced by Eu codoping. Both structural parameters and magnetic properties demonstrate the existence of an interaction between Co and Eu ions. The observation of multiplet structures for the localized Co $3 d$ states in $\mathrm{x}$-ray absorption and x-ray magnetic circular dichroism characterization evidences that the codoped Eu plays an important role in facilitating the Co substitution of $\mathrm{Zn}$, leading to intrinsic ferromagnetism. (C) 2010 American Institute of Physics. [doi:10.1063/1.3298507]
\end{abstract}

\section{INTRODUCTION}

Diluted magnetic semiconductors (DMSs) have attracted enormous interests because of their potential for innovative spintronics application. ${ }^{1,2}$ Currently, the most common DMSs are II-VI and III-V compounds (such as CdTe, ZnSe, $\mathrm{CdSe}, \mathrm{ZnO}, \mathrm{GaN}, \mathrm{GaAs}$, etc.), with transition metal ions (e.g., $\mathrm{Mn}, \mathrm{Fe}$, or $\mathrm{Co}$ ) substituting their original cations. Although values of Curie temperature above room temperature have been reported in Co-doped $\mathrm{TiO}_{2},{ }^{3} \mathrm{ZnO},{ }^{4}$ and $\mathrm{Mn}$-doped $\mathrm{GaN},{ }^{5}$ the possibility of an extrinsic origin of the ferromagnetism, such as ferromagnetic impurity segregation, could not be ruled out in most cases. It was reported that the nanoscale ferromagnetic phase in Co-doped $\mathrm{ZnO}$ thin films is due to the Co clusters. ${ }^{6}$ This gives rise to an argument: homogeneous films of $(\mathrm{Zn}, \mathrm{Co}) \mathrm{O}$ exhibited a spin-glass behavior while room temperature ferromagnetism was only found in inhomogeneous films attributed to the presence of Co clusters. ${ }^{7}$ Such an argument on the origin of ferromagnetism in $(\mathrm{Zn}, \mathrm{Co}) \mathrm{O}$ is caused by the often-performed magnetization measurements with a magnetometer [e.g., superconducting quantum interference device (SQUID)], which is unable to distinguish an intrinsic ferromagnetic signal from an extrinsic one. ${ }^{8}$ Recent progress for the investigation of the nature of ferromagnetism in $(\mathrm{Zn}, \mathrm{Co}) \mathrm{O}$ with other advanced materials characterization tools provides a better way to develop the intrinsic DMS materials. Although ion implantation is a common and simple technique to fabricate semiconductor materials with the advantage of creating nonequilibrium doping suited for achieving desired dopant concentrations, it was reported that the occurrence of Co clustering is frequently observed in the $(\mathrm{Zn}, \mathrm{Co}) \mathrm{O}$ thin films prepared by the ion implantation technique. ${ }^{9}$ This has impeded the application of ion implantation in the fabrication of DMSs. Therefore, the

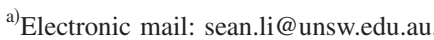

development of dilute magnetic-impurity-doped functional wide-bandgap semiconductors, such as $(\mathrm{Zn}, \mathrm{Co}) \mathrm{O}$, with hightemperature ferromagnetism is eagerly awaited if it is unambiguously established to be intrinsic in nature. ${ }^{8}$ In this study, we report the experimental evidence of Co substitution in $\mathrm{ZnO}$ epitaxial films induced by $\mathrm{Co}$ and Eu codoping as well as the results on the localized magnetic moment of $\mathrm{Co}$ in $\mathrm{Zn}_{0.92} \mathrm{Co}_{0.04} \mathrm{Eu}_{0.04} \mathrm{O}$ determined by $\mathrm{x}$-ray absorption spectroscopy (XAS) and x-ray magnetic circular dichroism (XMCD).

\section{EXPERIMENT}

The $\mathrm{Zn}_{96} \mathrm{Co}_{0.04} \mathrm{O}$ and $\mathrm{Zn}_{0.92} \mathrm{Co}_{0.04} \mathrm{Eu}_{0.04} \mathrm{O}$ materials were prepared by ion implantation. ${ }^{10}$ The $\mathrm{ZnO}$ (0001) epitaxial thin film, $\sim 100 \mathrm{~nm}$ thick grown on $c$-sapphire, was implanted with $\mathrm{Co}$ and $\mathrm{Eu}$ ion beams perpendicular to its surface under a vacuum pressure of $2 \times 10^{-6}$ mbar. The TRIM calculation ${ }^{11}$ was performed to optimize implanting parameters for the $\mathrm{ZnO}$ epitaxial thin film. For the codoped sample of $\mathrm{Zn}_{0.92} \mathrm{Co}_{0.04} \mathrm{Eu}_{0.04} \mathrm{O}$, Co was implanted first followed by Eu. The dose concentrations and the ion distribution depth profiles were verified by Rutherford back scattering (RBS) measurements. At the above mentioned implantation parameters, both $\mathrm{Co}$ and Eu have an average concentration of $4 \%$. The crystallographic structures of the as-prepared materials were characterized using X'Pert PRO Materials Research Diffractometer that is specially designed for $\mathrm{X}$-ray diffraction (XRD) characterization of thin films with $\mathrm{Cu} \mathrm{K} \alpha_{1}$ radiation. The magnetic properties of doped $\mathrm{ZnO}$ films were determined using a SQUID magnetometer (Quantum Design MPMS-XL). Local electronic structure and magnetic moments of Co were studied by XAS and XMCD at BL11A Dragon beamline of National Synchrotron Radiation Research Centre in Taiwan. XAS spectra at the Co $L_{2,3}$ edge were measured in total fluorescence yield mode to probe the properties throughout the entire thickness of the films at both 


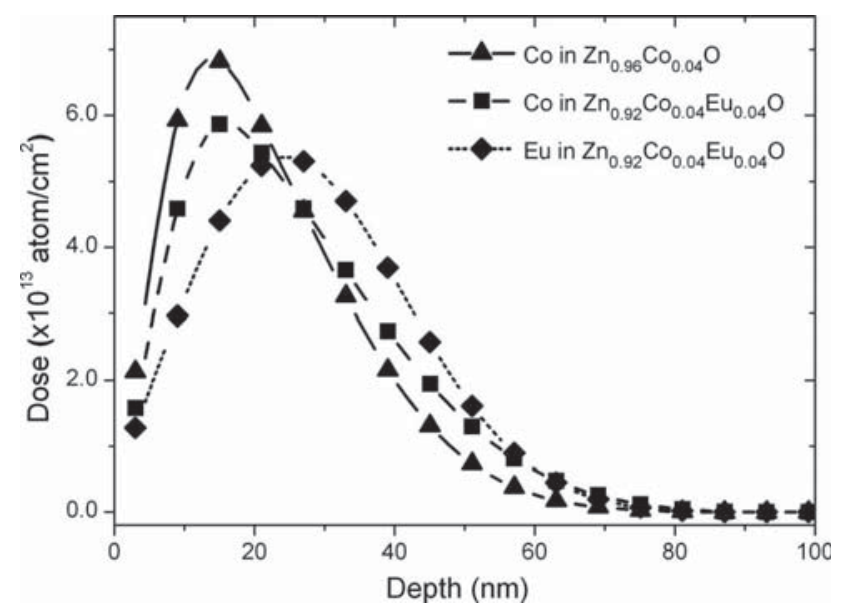

FIG. 1. Distribution of $\mathrm{Co}$ and Eu ions as a function of depth. $\mathrm{X}$ axis is depth (nanometer) from the top surface and $\mathrm{Y}$ axis is Co or Eu dose at a particular depth.

room temperature and $77 \mathrm{~K}$. The propagation direction of the incident circular polarized $\mathrm{x}$-ray $(\sim 80 \%$ polarization $)$ was $30^{\circ}$ with respect to the surface of the samples. A magnetic field of $1 \mathrm{~T}$ was applied along the surface plane of the samples. XMCD spectra originated from the difference of the spin-resolved XAS corresponding to two opposite magnetic fields after proper background subtraction.

\section{RESULTS AND DISCUSSION}

Figure 1 shows the depth profiles of $\mathrm{Co}$ and $\mathrm{Eu}$, which are analyzed with RBS measurement, in the as-prepared thin films. It is discernable that the peak of Co depth profile in $\mathrm{Zn}_{0.96} \mathrm{Co}_{0.04} \mathrm{O}$ (the sample with Co dopants only) is located at $\sim 15 \mathrm{~nm}$ underneath the film surface. The subsequent $\mathrm{Eu}$ implantation changed the implanted Co distribution profile of depth. Although the peak position of Co depth profile remains unchanged, Co distribution profile broadens, having more $\mathrm{Co}$ in the depth range of $>25 \mathrm{~nm}$ by comparing to $\mathrm{Zn}_{0.96} \mathrm{Co}_{0.04} \mathrm{O}$. In $\mathrm{Zn}_{0.96} \mathrm{Co}_{0.04} \mathrm{Eu}_{0.04} \mathrm{O}$, the peak of Eu depth profile is positioned at $\sim 26 \mathrm{~nm}$, similar to the depth estimated by TRIM calculation. It is noted that in this work our strategy is to maintain the similarity of Co distribution profiles between the Co-doped $\mathrm{ZnO}$ film and the $\mathrm{Co}-\mathrm{Eu}$ codoped $\mathrm{ZnO}$ film to investigate the subtle interplay between $\mathrm{Co}$ and $\mathrm{Eu}$.

XRD spectra of $\mathrm{ZnO}, \quad \mathrm{Zn}_{96} \mathrm{Co}_{0.04} \mathrm{O}$, and $\mathrm{Zn}_{0.92} \mathrm{Co}_{0.04} \mathrm{Eu}_{0.04} \mathrm{O}$ thin films in Fig. 2 show that the asimplanted films were single phase with a wurtzitelike structure. No secondary phases including $\mathrm{Co}$ and $\mathrm{Eu}$ alloys were detected in the samples. The strong and sharp (0002) diffraction found in the as-grown $\mathrm{ZnO}$ film shows that the $\mathrm{ZnO}$ film was well crystallized. A small left shift of the (0002) peak appearing in $\mathrm{Zn}_{0.96} \mathrm{Co}_{0.04} \mathrm{O}$ demonstrates the expansion of $c$ lattice parameter caused by Co dopants. The $c$ was expanded from $5.2084 \AA$ for the $\mathrm{ZnO}$ film to $5.2099 \AA$ for the $\mathrm{Zn}_{0.96} \mathrm{Co}_{0.04} \mathrm{O}$. It was reported that the substitution of $\mathrm{Zn}^{2+}$ (ion radius of $0.60 \AA$ ) with high-spin $\mathrm{Co}^{2+}$ (ion radius of 0.58 $\AA$ ) in tetrahedral coordination results in the reduction in $c$ with large compressive strain. ${ }^{4,12}$ Therefore, the expansion of

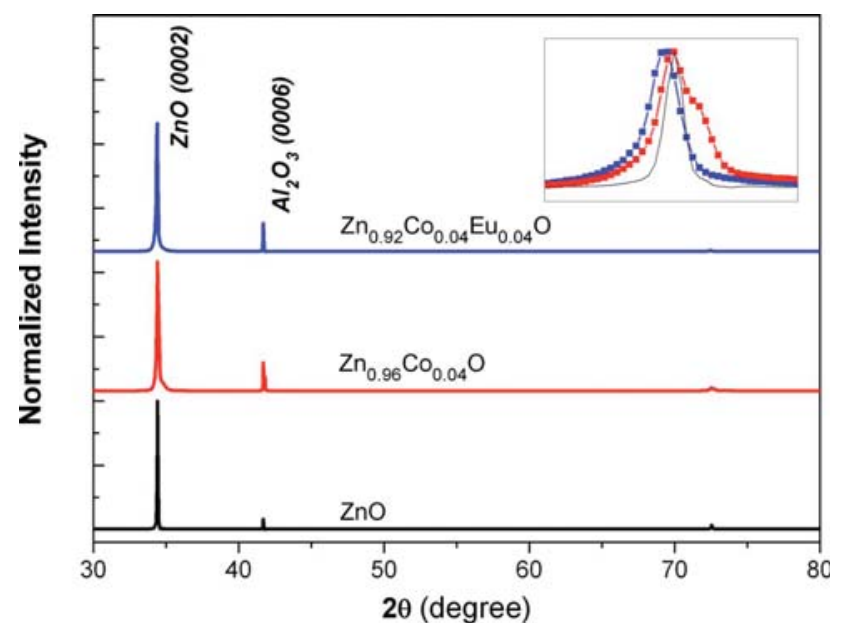

FIG. 2. (Color online) $\theta$-2 $\theta$ XRD patterns of $\mathrm{ZnO}, \mathrm{Zn}_{0.96} \mathrm{Co}_{0.04} \mathrm{O}$, and $\mathrm{Zn}_{0.92} \mathrm{Co}_{0.04} \mathrm{Eu}_{0.04} \mathrm{O}$ thin films. Inset shows the normalized (0002) peak.

$c$ induced by Co suggests that Co ions do not fully substitute $\mathrm{Zn}$ in the wurtzite lattice points with +2 formal oxidation state. It implies that the Co ions may exist with the form of either Co metal nanoclustering or the interstices accommodated in octahedral interstitial sites of the wurtzite structure or both in $\mathrm{Zn}_{0.96} \mathrm{Co}_{0.04} \mathrm{O}$. The lattice constant $c$ of the Co and Eu codoped sample $\mathrm{Zn}_{0.92} \mathrm{Co}_{0.04} \mathrm{Eu}_{0.04} \mathrm{O}$ is $5.2127 \AA$ which is larger than that of $\mathrm{Zn}_{0.96} \mathrm{Co}_{0.04} \mathrm{O}$. It is understandable that the addition of large $\mathrm{Eu}$ ions into the Co-doped $\mathrm{ZnO}$ can result in a larger $c$ than that of $\mathrm{Zn}_{0.96} \mathrm{Co}_{0.04} \mathrm{O}$ due to the substantial difference of ion radii between $\mathrm{Zn}$ and $\mathrm{Eu}$, where the radii of $\mathrm{Eu}^{2+}$ and $\mathrm{Eu}^{3+}$ are 1.17 and $1.03 \AA$, respectively. ${ }^{13}$ The normalized (0002) peaks are shown in the inset of Fig. 2. It is found that the peak of $\mathrm{Zn}_{96} \mathrm{Co}_{0.04} \mathrm{O}$ is asymmetrical and looks like consisting of two peaks in the first glance. However, if it were true, the other peaks of a secondary phase should be observed in the XRD spectra. So the observed phenomenon may be due to inhomogeneous distribution of $\mathrm{Co}$ in the Co-doped $\mathrm{ZnO}$ film. Furthermore, the full width at half maximum of the (002) peak reduces remarkably for $\mathrm{Zn}_{0.92} \mathrm{Co}_{0.04} \mathrm{Eu}_{0.04} \mathrm{O}$ compared to that for $\mathrm{Zn}_{96} \mathrm{Co}_{0.04} \mathrm{O}$. These strongly indicate that $\mathrm{Eu}$ and $\mathrm{Co}$ couples to reduce inhomogeneous strain, meaning the existence of a subtle interaction between $\mathrm{Co}$ and $\mathrm{Eu}$ in the codoped materials. The coupling of the compressive and tensile strains caused by the doped $\mathrm{Co}$ and Eu individually can minimize the energy of system. This may break the network of the Co metal nanoclusters, thus enhancing Co substitution at $\mathrm{Zn}$ lattice sites.

Figure 3 shows isothermal magnetization curves of $\mathrm{Zn}_{0.92} \mathrm{Co}_{0.04} \mathrm{Eu}_{0.04} \mathrm{O}$ and $\mathrm{Zn}_{0.96} \mathrm{Co}_{0.04} \mathrm{O}$ as a function of the external magnetic field applied parallel to the film surface. It demonstrates that $\mathrm{Zn}_{0.92} \mathrm{Co}_{0.04} \mathrm{Eu}_{0.04} \mathrm{O}$ and $\mathrm{Zn}_{0.96} \mathrm{Co}_{0.04} \mathrm{O}$ possesses ferromagnetism at room temperature with a coercive field of 60 Oe as shown in the hysteresis loop. The saturation magnetization $\left(M_{\mathrm{s}}\right)$ of $65 \mathrm{emu} / \mathrm{cm}^{3}$, equivalent to $2.09 \mu_{\mathrm{B}} /(\mathrm{Co}+\mathrm{Eu})$, with the remanent magnetization of $5.2 \mathrm{emu} / \mathrm{cm}^{3}$ and the $M_{\mathrm{s}}$ of $50 \mathrm{emu} / \mathrm{cm}^{3}$, equivalent to $3.21 \mu_{\mathrm{B}} / \mathrm{Co}$, with the remanent magnetization of $3.0 \mathrm{emu} / \mathrm{cm}^{3}$ were determined for $\mathrm{Zn}_{0.92} \mathrm{Co}_{0.04} \mathrm{Eu}_{0.04} \mathrm{O}$ and $\mathrm{Zn}_{0.96} \mathrm{Co}_{0.04} \mathrm{O}$, respectively. The presence of ferromagnetism 


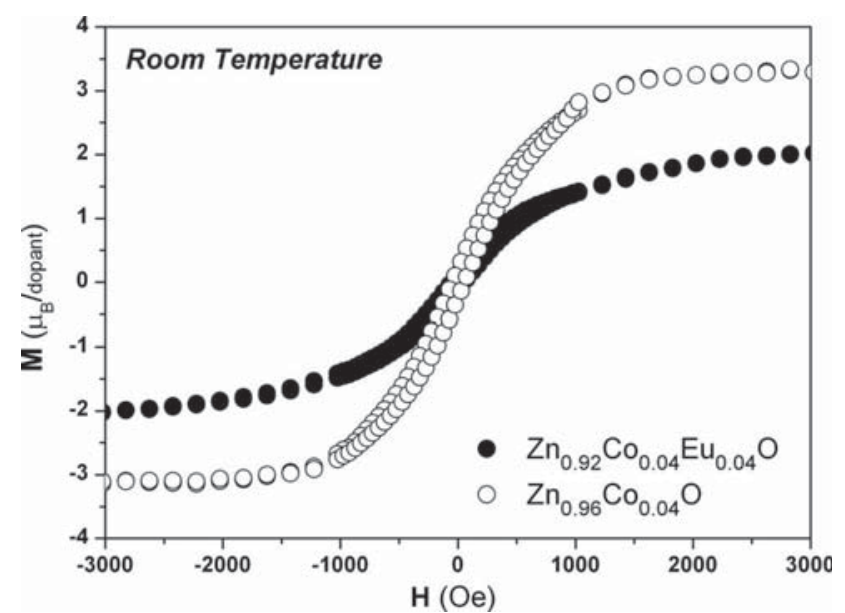

FIG. 3. Magnetization curves of $\mathrm{Zn}_{0.92} \mathrm{Co}_{0.04} \mathrm{Eu}_{0.04} \mathrm{O}$ and $\mathrm{Zn}_{0.96} \mathrm{Co}_{0.04} \mathrm{O}$ thin films measured by a SQUID magnetometer at room temperature, after the subtraction of diamagnetic contribution of $\mathrm{Al}_{2} \mathrm{O}_{3}$ substrate. The external applied field was applied parallel to the film surface. (Note: dopants for $\mathrm{Zn}_{0.92} \mathrm{Co}_{0.04} \mathrm{Eu}_{0.04} \mathrm{O}$ and $\mathrm{Zn}_{0.96} \mathrm{Co}_{0.04} \mathrm{O}$ refer to $\mathrm{Co}+\mathrm{Eu}$ and $\mathrm{Co}$, respectively.)

in $\mathrm{Zn}_{0.96} \mathrm{Co}_{0.04} \mathrm{O}$ supports Co's clustering in the film. The ferromagnetism in $\mathrm{Zn}_{0.92} \mathrm{Co}_{0.04} \mathrm{Eu}_{0.04} \mathrm{O}$ may be sourced from the substitution of the implanted Co and Eu. Our theoretical studies using ab initio calculations show that $\mathrm{Eu}$ dopants in the $\mathrm{ZnO}$ host lattice are preferably substitutional at the $\mathrm{Zn}$ site by examining three different possible cases: (i) the octahedral interstitial site of the perfect hexagonal $\mathrm{ZnO}$ lattice, (ii) the octahedral interstitial site where a neighboring $\mathrm{Zn}$ vacancy exists, and (iii) the substitutional $\mathrm{Zn}$ site. Total energy calculations show that in $\mathrm{Zn}_{0.875} \mathrm{Co}_{0.0625} \mathrm{Eu}_{0.0625} \mathrm{O}$, the ferromagnetic interaction between $\mathrm{Co}$ and $\mathrm{Eu}$ is stronger than the ferrimagnetic one where the spin alignment of $\mathrm{Eu}$ and Co ions is antiparallel.

Figure 4 shows XAS and XMCD spectra of the Co $L_{2,3}$ edge of $\mathrm{Zn}_{0.92} \mathrm{Co}_{0.04} \mathrm{Eu}_{0.04} \mathrm{O}$ measured at room temperature and $77 \mathrm{~K}$. The absorption at the Co $L_{2,3}$ edge is associated with Co $2 p$ to $3 d$ transition, which provides information of unoccupied density of Co $3 d$ states by probing the projected

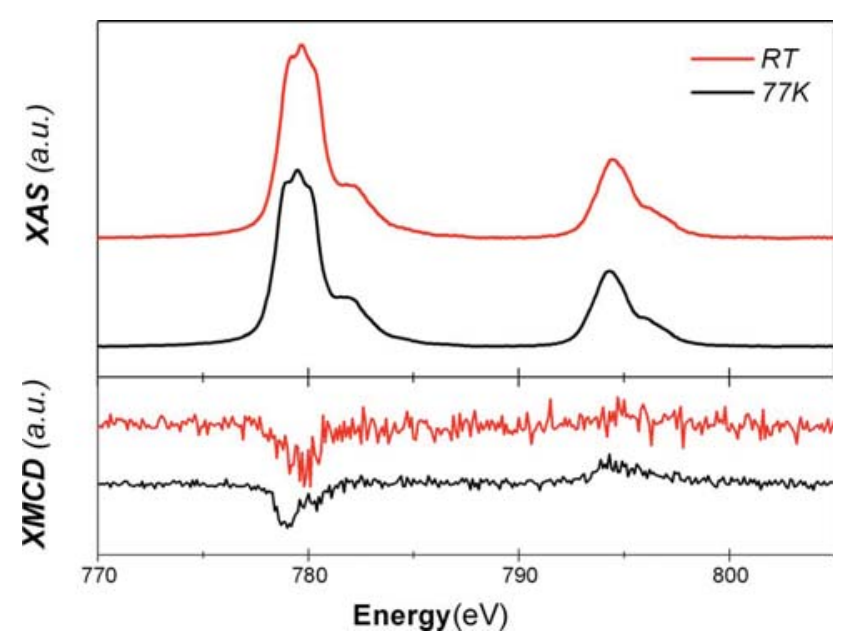

FIG. 4. (Color online) XAS spectra (top) and their derived XMCD spectra (bottom) of $\mathrm{Zn}_{0.92} \mathrm{Co}_{0.04} \mathrm{Eu}_{0.04} \mathrm{O}$ measured at the Co $L_{2,3}$ absorption edges at room temperature and $77 \mathrm{~K}$.

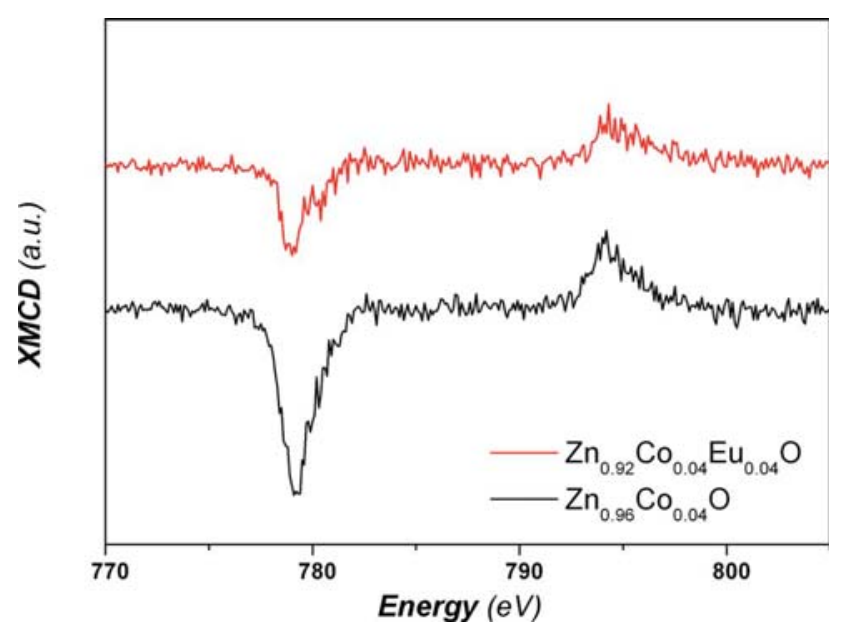

FIG. 5. (Color online) XMCD spectra of $\mathrm{Zn}_{0.92} \mathrm{Co}_{0.04} \mathrm{Eu}_{0.04} \mathrm{O}$ and $\mathrm{Zn}_{0.96} \mathrm{Co}_{0.04} \mathrm{O}$ measured at the Co $L_{2,3}$ absorption edges at $77 \mathrm{~K}$.

$3 d$ magnetism of Co. ${ }^{14}$ It can be seen from the XAS and XMCD spectra that the absorption at Co $L_{2}$ and $L_{3}$ is different from those of Co metals. By comparing with the theoretical XAS results, ${ }^{15}$ it is discernable that the observed tetrahedral multiple structures are consistent with the local electronic structure of Co substitution at the tetrahedral $\mathrm{Zn}$ site. This provides strong evidence of Co substitution induced by the Eu codoping. From our comprehensive investigation with first-principles density functional calculations, it is interesting to find that the possibility of $\mathrm{Eu}^{2+}$ and $\mathrm{Eu}^{3+}$ coexistence can be ruled out and only $\mathrm{Eu}^{2+}$ can appear in the materials with the spinning state of 7 . This detail work will be reported in elsewhere. The Co magnetic spin moment $\left(m_{\mathrm{s}}\right)$ of $\mathrm{Zn}_{0.92} \mathrm{Co}_{0.04} \mathrm{Eu}_{0.04} \mathrm{O}$ derived from XMCD sum rules ${ }^{16}$ is $0.082 \pm 0.020 \mu_{\mathrm{B}}$ per $\mathrm{Co}$ atom at room temperature and $0.096 \pm 0.014 \mu_{\mathrm{B}}$ per Co atom at $77 \mathrm{~K}$. It suggests that the temperature has very limit effects on the localized magnetic spin moment of $\mathrm{Co}$ in $\mathrm{Zn}_{0.92} \mathrm{Co}_{0.04} \mathrm{Eu}_{0.04} \mathrm{O}$. XMCD spectra of the Co $L_{2,3}$ edge of $\mathrm{Zn}_{0.92} \mathrm{Co}_{0.04} \mathrm{Eu}_{0.04} \mathrm{O}$ and $\mathrm{Zn}_{0.96} \mathrm{Co}_{0.04} \mathrm{O}$ measured at $77 \mathrm{~K}$ are compared in Fig. 5. The $m_{\mathrm{s}}$ of Co in $\mathrm{Zn}_{0.96} \mathrm{Co}_{0.04} \mathrm{O}$ is $0.191 \pm 0.016 \mu_{\mathrm{B}}$ per $\mathrm{Co}$ atom at $77 \mathrm{~K}$, which is obviously larger than that for $\mathrm{Zn}_{0.92} \mathrm{Co}_{0.04} \mathrm{Eu}_{0.04} \mathrm{O}$. The large magnetic spin moment from the $\mathrm{Zn}_{0.96} \mathrm{Co}_{0.04} \mathrm{O}$ may be contributed from Co metal nanoclusters presented in the sample. On the other hand, the smaller Co magnetic spin moment in $\mathrm{Zn}_{0.92} \mathrm{Co}_{0.04} \mathrm{Eu}_{0.04} \mathrm{O}$ may be caused by enhanced Co substitution in $\mathrm{Zn}_{0.92} \mathrm{Co}_{0.04} \mathrm{Eu}_{0.04} \mathrm{O}$, indicating a strong interaction between $\mathrm{Co}$ and $\mathrm{Eu}$ in the codoped sample. This is in agreement with aforementioned magnetic properties which further supports the notion that the Co substitution was facilitated by Eu codoping in $\mathrm{ZnO}$.

It is well known that the Co metal nanoclustering easily forms in vacuum processing environment. It is often observed in the samples prepared with ion implantation techniques, ${ }^{9}$ thus resulting in the large localized spin moments. ${ }^{17}$ Consequently this process may facilitate the replacement of $\mathrm{Zn}$ with $\mathrm{Co}$ in the wurtzite lattice. Therefore, the Co magnetic contribution in $\mathrm{Zn}_{0.92} \mathrm{Co}_{0.04} \mathrm{Eu}_{0.04} \mathrm{O}$ thin films would arise from the intrinsic Co substituting $\mathrm{Zn}$. The energy of Eu $L$ edge is too high to be determined due to the 
facility measurement limit. Since the signal at $M_{4,5}$ edge in our measurement is very weak with a strong background of noise, it leaves an open question on the measurement of magnetic spin and orbit moments of Eu for future investigation. It is believed that the Co-Co spin coupling in perfect $\mathrm{ZnO}$ lattice structure is antiparallel, ${ }^{18}$ similar to Eu-Eu spin coupling. However, total energies calculations show that in its most stable configuration of $\mathrm{Zn}_{0.875} \mathrm{Co}_{0.0625} \mathrm{Eu}_{0.0625} \mathrm{O}$ parallel Co-Eu spin coupling is stronger by $57 \mathrm{meV}$ than antiparallel. Therefore, the magnetic contribution in $\mathrm{Zn}_{0.92} \mathrm{Co}_{0.04} \mathrm{Eu}_{0.04} \mathrm{O}$ thin films would arise from the ferromagnetic interaction between substitutional $\mathrm{Co}$ and $\mathrm{Eu}$. Atomic ratio of $\mathrm{Co}$ and $\mathrm{Eu}$ needs to be optimized to achieve the best performance. A systematic study on the detailed interaction between $\mathrm{Co}$ and $\mathrm{Eu}$ on crystal and electrical structures with XAS to analyze the extended x-ray absorption fine structure is currently in progress. Furthermore, the room temperature photoluminescence was used to determine the structural disordering induced by the implantation process and its results show no artifact is induced during the materials preparation.

\section{CONCLUSION}

We have studied the structural and magnetic properties of $\mathrm{Zn}_{0.92} \mathrm{Co}_{0.04} \mathrm{Eu}_{0.04} \mathrm{O}$ thin films prepared by ion implantation technique. Room temperature ferromagnetism was observed with a saturation magnetization of $65 \mathrm{emu} / \mathrm{cm}^{3}$, a coercivity of 60 Oe and a remanent magnetization of $5.2 \mathrm{emu} / \mathrm{cm}^{3}$. XAS spectra of Co $L_{2,3}$ edge show that the Co ions reside in the tetrahedral coordination, demonstrating its substitution of $\mathrm{Zn}$ in the wurtzite structure. XMCD spectra of Co $L_{2,3}$ edge also reveal that Co metal nanoclustering may not form in $\mathrm{Co}$ and $\mathrm{Eu}$ coimplanted $\mathrm{ZnO}$ as evidenced by $\mathrm{Co}$ tetrahedral multiplet structures. It suggests that Co substitution at the $\mathrm{Zn}$ sites may be facilitated by Eu codoping and thus the Co metal clustering is suppressed significantly.

\section{ACKNOWLEDGMENTS}

This work was supported by Australian Research Council (Grant Nos. ARC DP0988687 and DP0770424) and Australian Institute of Nuclear Science and Engineering (AINSE Grant No. AINGRA06245). XAS and XMCD experiments at National Synchrotron Radiation Research Centre in Taiwan were assisted by H. J. Lin and F. H. Chang and supported by Australian Synchrotron Research Program.

${ }^{1}$ F. Matsukura, H. Ohno, A. Shen, and Y. Sugawara, Phys. Rev. B 57, R2037 (1998)

${ }^{2}$ H. Ohno, Science 281, 951 (1998).

${ }^{3}$ J. Y. Kim, J. H. Park, B. G. Park, H. J. Noh, S. J. Oh, J. S. Yang, D. H. Kim, S. D. Bu, T. W. Noh, H. J. Lin, H. H. Hsieh, and C. T. Chen, Phys. Rev. Lett. 90, 017401 (2003).

${ }^{4}$ A. S. Risbud, N. A. Spaldin, Z. Q. Chen, S. Stemmer, and R. Seshadri, Phys. Rev. B 68, 205202 (2003).

${ }^{5}$ M. L. Reed, N. A. El-Masry, H. H. Stadelmaier, M. K. Ritums, K. J. Reed, C. A. Parker, J. C. Roberts, and S. M. Bedair, Appl. Phys. Lett. 79, 3473 (2001).

${ }^{6}$ J. H. Park, K. G. Kim, H. M. Jang, S. Ryu, and Y. M. Kim, Appl. Phys. Lett. 84, 1338 (2004).

${ }^{7}$ J. H. Kim, H. Kim, D. Kim, Y. E. Ihm, and W. K. Choo, J. Appl. Phys. 92, 6066 (2002).

${ }^{8}$ N. Samarth, Nature Mater. 6, 403 (2007).

${ }^{9}$ D. P. Norton, M. E. Overberg, S. J. Pearton, K. Pruessner, J. D. Budai, L. A. Boatner, M. F. Chisholm, J. S. Lee, Z. G. Khim, Y. D. Park, and R. G. Wilson, Appl. Phys. Lett. 83, 5488 (2003).

${ }^{10}$ P. J. Evans, G. C. Watt, and J. T. Noorman, Rev. Sci. Instrum. 65, 3082 (1994).

${ }^{11}$ J. F. Ziegler, Nucl. Instrum. Methods Phys. Res. B 219-220, 1027 (2004).

${ }^{12}$ Z. Jin, M. Murakami, T. Fukumura, Y. Matsumoto, A. Ohtomo, M. Kawasaki, and H. Koinuma, J. Cryst. Growth 214-215, 55 (2000).

${ }^{13}$ H. Choi, C. H. Kim, C. H. Pyun, and S. J. Kim, J. Solid State Chem. 138, 149 (1998).

${ }^{14}$ T. Tietze, M. Gacic, G. Schutz, G. Jakob, S. Bruck, and E. Goering, New J. Phys. 10, 055009 (2008).

${ }^{15}$ M. Kobayashi, Y. Ishida, J. Hwang, T. Mizokawa, A. Fujimori, K. Mamiya, J. Okamoto, Y. Takeda, T. Okane, Y. Saitoh, Y. Muramatsu, A. Tanaka, H. Saeki, H. Tabata, and T. Kawai, Phys. Rev. B 72, 201201 (2005).

${ }^{16}$ C. T. Chen, Y. U. Idzerda, H. J. Lin, N. V. Smith, G. Meigs, E. Chaban, G. H. Ho, E. Pellegrin, and F. Sette, Phys. Rev. Lett. 75, 152 (1995).

${ }^{17}$ F. Pan, C. Song, X. J. Liu, Y. C. Yang, and F. Zeng, Mater. Sci. Eng. R. 62, 1 (2008).

${ }^{18}$ Y. B. Zhang, M. H. N. Assadi, and S. Li, J. Phys.: Condens. Matter 21, 175802 (2009). 